\title{
Mapping of selected coral reefs in Southern, Sri Lanka using remote sensing methods
}

\author{
T.W.S. WARNASURIYA ${ }^{1 *}$, P.B. TERNEY PRADEEP KUMARA and N. \\ ALAHACOON
}

Department of Oceanography and Marine Geology, Faculty of Fisheries and Marine Sciences \& Technology, University of Ruhuna, Matara, Sri Lanka

${ }^{1}$ Present address: Department of Fisheries and Marine Science, Ocean University of Sri Lanka, Mahawela Road, Tangalle, Sri Lanka

* Corresponding author (sameethocg@gmail.com)

\begin{abstract}
Most parts of the Southern coastal belt of Sri Lanka are fringed with shallow water coral reefs of high economic, ecological and socioeconomic attributes. Polhena, Madiha and Dondra are some of the places where the isolated coral reefs are located in this region. Descriptive details such as the extent, reef margins, and coral compositions of these reefs are lacking due to the difficulties of accessibility, harsh conditions and the lacking of trained expertise for reef mapping. Remote sensing can be used as a tool to identify the reef locations, spatial distribution, bottom nature, present status of the reef area for their effective management and conservation. In this research, bathymetry maps were produced using 'Depth of Penetration' method for Landsat7 ETM+ satellite images. Image band $1(0.45-0.515 \mu \mathrm{m})$, band2 $(0.525$ $0.605 \mu \mathrm{m})$, band $3(0.63-0.69 \mu \mathrm{m})$ and band $4(0.75-0.9 \mu \mathrm{m})$ have been used as main inputs of bathymetry mapping. Colour composites, classified images and manually digitized images were used to map the spatial pattern of the reefs. The image processing has been carried out with ILWIS 3.3 and ArcGIS 9.3 software. Created maps were validated using ground truth data which were taken during the field survey. The Pearson correlation coefficient $(\mathrm{r}=0.921)$ indicates that there is a high correlation between true depth and the calculated depth from the map. The standard error of the estimate is 0.85 . According to the created GIS maps, maximum depth $(1.83 \pm 0.79 \mathrm{~m})$ was recorded in Dondra reef while lowest depth $(1.46 \pm 1.23 \mathrm{~m})$ was recorded in Polhena reef. Depth of the madiha reef was $1.81 \pm 0.99 \mathrm{~m}$. Highest reef area represented by the Polhena reef $\left(240300 \mathrm{~m}^{2}\right)$ while lowest area represented by the Madiha reef $\left(51300 \mathrm{~m}^{2}\right)$. Area of the Dondra reef was $85500 \mathrm{~m}^{2}$. Band 4 is the best for shallow $(<4 \mathrm{~m})$ reef mapping and high resolution images are ideal for more detailed habitat mapping.
\end{abstract}

Keywords: Coral Reefs, Remote sensing, Landsat7 ETM+, Bathymetry, Sri Lanka 


\section{Introduction}

Coral reefs are one of the major and diverse ecosystems in marine environment which provide the ideal habitat for many marine organisms such as fish, mollusks, crustaceans, echinoderms, sponges, tunicates and other cnidarians (Hoover 1998). Most parts of the Southern coastal belt of Sri Lanka are fringed with shallow water coral reefs of high economic, ecological and socioeconomic attributes. The structure and the distribution of coral reef of Sri Lanka have believed to be altered mainly due to anthropogenic activities on coral reefs such as, dynamite fishing, coral mining, pollution, human settlement, mineral mining, shipping activities and intensive fish collection for the live fish and the aquarium trade (Pradeep Kumara et al. 2005) and environmental impacts such as 1998 El Niño event (Wilkinson et al. 1999 cited in Pradeep Kumara et al. 2005) and 2004 tsunami.

Major constraints of the coral reef management and conservation is the lack of understanding on the exact reef extent, distribution, reef margins, coral compositions and recent alterations of reef structure. Many studies had been conducted in mapping of coral reef distribution in the world using different field surveying techniques. Most of them are not cost effective, time consuming and all the techniques cannot be applied for all geographical locations due to the difficulties of accessibility, harsh conditions and the lacking of trained expertise for reef mapping. A novel tool, which is the use of remote sensing technique is successfully applied in other regions in determining the distribution and size of reefs (Mumby et al. 1997).

For identification of coral reefs, bathymetry map can be used as a base map (Vanderstraete et al. 2003). There are several methods used for bathymetry mapping (Nadaoka, et al. 2004). Out of them the "Depth of Penetration" mapping method developed by Jupp (1988) was the most accurate. Later it was modified by Green et al. (2000) and Vanderstraete et al. (2003).There are three assumptions, viz light attenuation is an exponential function of depth, water quality does not vary within the image and substrate does not vary within the image (Vanderstraete et al. 2003). The objective of the study was to determine the possibility of applying GIS and remote sensing tool in developing the coral reef maps in Sri Lankan waters.

\section{Materials and Methods}

\section{Study area}

Study area lies along the coastline from Madiha $\left(5^{\circ} 56^{\prime} 09.00^{\prime \prime} \mathrm{N}, 80^{\circ} 30^{\prime}\right.$ $\left.44.00^{\prime \prime} \mathrm{E}\right)$ to Dondra ( $\left.5^{\circ} 55^{\prime} 12.00^{\prime \prime} \mathrm{N}, 80^{\circ} 35^{\prime} 40.00^{\prime \prime} \mathrm{E}\right)$ where some shallow coral reefs (Madiha, Polhena and Dondra reefs) are located (Figure 1). These areas are subjected to south-west monsoon from May to August and the dry season is from December to March (Joseph 2005). During that south-west 
monsoon period the sea is rough compared to other seasons of the year. Annual rainfall is over $2000 \mathrm{~mm}$ and annual temperature is around $27^{\circ} \mathrm{C}$.

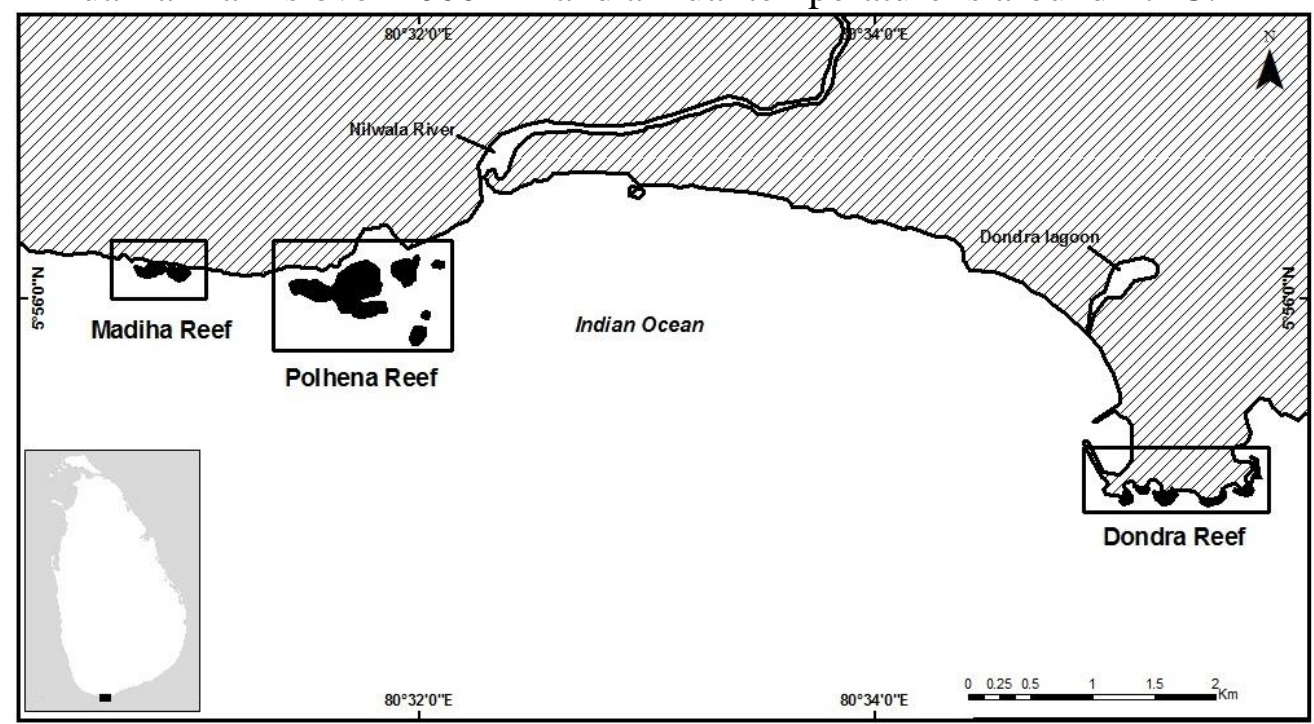

Figure 1. Study area of the southern coast, Sri Lanka.

\section{Field data collection}

Field survey was carried out during February and March in 2012 to get depths and GPS locations of the reef areas. 336 depth values were taken using depth gauge and the geographical locations of the depth points were measured using a handheld Garmin GPS. Accuracy of the GPS is $4 \mathrm{~m}$.

\section{Hydrographic chart data collection}

Hydrographic chart provided by National Hydrographic Office of National Aquatic Resources Research and Development Agency (NARA) was used in order to obtain deep water depths $(>50 \mathrm{~m})$ and few depths at the reef area. 252 depth values were found from the chart with the $\mathrm{X}$ and $\mathrm{Y}$ coordinates. Coordinates were in WGS84 and the map projection was Universal Transverse Mercator (UTM).

\section{Satellite data collection}

Landsat7 ETM+ images acquired on 05 February 2005 were used (Path-141, Row-056). Out of eight bands of the Landsat images, band 1, 2, 3 and 4 were used. They were already geo-referenced according to the WGS84 coordinate system at the moment of the image downloading. They have been projected according to the UTM projection. Wave lengths of band 1, 2 and 3 are in the 
visible range represent by blue, green, and red respectively. Band 4 is in the near infrared (NIR) region of the electromagnetic spectrum. Spatial resolution of these bands is $30 \mathrm{~m}$.

\section{Image processing}

Image processing was carried out using ILWIS 3.3 software and Arc GIS 9.3 software for sub maps created from Band 1, 2, 3 and 4. Minimum X, Y of a sub map was respectively $444330.000 \& 652350.000$ and Maximum X, Y was respectively $455730.000,658260.000$. Different Colour composites were created by combining three bands at once.

'Depth of Penetration' (DOP) mapping method which is developed by Jupp (1988) and modified by Green et al. (2000) and Vanderstraete (2003) was used for the bathymetry mapping and depths within DOP zones were calibrated and interpolated according to the two-flow radiative transfer model as follow:

$\mathrm{L}_{\mathrm{i}}=\mathrm{L}_{\mathrm{i} \infty \text { mean }}+\left(\mathrm{L}_{\mathrm{i} \text { surface }}-\mathrm{L}_{\mathrm{i} \infty \text { mean }}\right) \mathrm{e}^{-2 \mathrm{ki} \mathrm{z}}$

where,

$\mathrm{L}_{\mathrm{i}}=$ Radiance measured at sensor

$\mathrm{L}_{\text {isomean }}=$ Average pixel valuefor band i over deep water, due to the reflection of the water column, the surface and scattering from the atmosphere

$\mathrm{L}_{\mathrm{i} \text { surface }}=$ Average $\mathrm{DN}$-value of the sandy bottom at sea level

$\mathrm{K}_{\mathrm{i}}=$ attenuation coefficient for band $\mathrm{i}$

$\mathrm{Z}=$ Depth

This relationship between radiance and depth was linearized using natural logarithms as below.

$\operatorname{Ln}\left(\mathrm{L}_{\mathrm{i}}-\mathrm{L}_{\mathrm{i} \infty \text { mean }}\right)=\mathrm{Ln}\left(\mathrm{L}_{\mathrm{i} \text { surface }}-\mathrm{L}_{\mathrm{i} \infty \text { mean }}\right)-2 \mathrm{k}_{\mathrm{i}} \mathrm{Z}$

To interpolate the depth, above equation was arranged as;

$\mathrm{Z}=\left(\mathrm{A}_{\mathrm{i}}-\mathrm{X}_{\mathrm{i}}\right) / 2 \mathrm{k}_{\mathrm{i}}$

where,

$A_{i}=L n\left(L_{i \text { surface }}-L_{i \infty \text { mean }}\right)$

$\mathrm{X}_{\mathrm{i}}=\mathrm{Ln}\left(\mathrm{L}_{\mathrm{i}}-\mathrm{L}_{\mathrm{i} \infty \text { mean }}\right)$ 
$\mathrm{L}_{\mathrm{i}}$ surface and $\mathrm{k}_{\mathrm{i}}$ are unknown parameters. Hence, the following approximations were used according to Jupp (1988), Green et al. (2000) and Vanderstraete (2003).

$\mathrm{A}_{\mathrm{i}}=\mathrm{X}_{\mathrm{i} \min }+2 \mathrm{Z}_{\mathrm{i}} \mathrm{k}_{\mathrm{i}}$

$\mathrm{k}_{\mathrm{i}}=\left(\mathrm{X}_{\mathrm{i} \max }-\mathrm{X}_{\mathrm{i} \min }\right) / 2\left(\mathrm{Z}_{\mathrm{i}}-\mathrm{Z}_{\mathrm{i}}+1\right)$

$\mathrm{X}_{\mathrm{i} \min } \& \mathrm{X}_{\mathrm{i} \max }$ can be expressed as;

$\mathrm{X}_{\mathrm{i} \min }=\mathrm{Ln}\left(\mathrm{L}_{\mathrm{i} \min }-\mathrm{L}_{\mathrm{i} \infty \text { mean }}\right)$

$\mathrm{X}_{\mathrm{imax}}=\mathrm{Ln}\left(\mathrm{L}_{\mathrm{i} \max }-\mathrm{L}_{\mathrm{i} \infty \text { mean }}\right)$

where,

$\mathrm{Z}_{\mathrm{i}}=$ maximum depth of penetration for DOP-zone $\mathrm{i}$

$\mathrm{Z}_{\mathrm{i}}+1=$ maximum depth of penetration of the overlaying DOP-zone

$\mathrm{L}_{\mathrm{i} \text { min }}=$ minimum $\mathrm{DN}$-value for each DOP zone

$\mathrm{L}_{\mathrm{i} \max }=$ maximum DN-value for each DOP zone

Several parameters and Digital Number (DN) values which are needed for above equations were found from the image bands separately by assigning field and hydrographic chart depth values for each band. Maximum penetration depth of wavelengths for each band was found using the depth values taken from the hydrographic charts which are corresponding to the deep water DN values. Deep water mean DN values of the study area for each band were estimated by getting the mean value of the maximum and minimum DN values of the deep waters. Final bathymetry map was created by combining the separate depth calculated bands. Subsequently the depth calculated bands were used to create map lists in the form of different combinations. Finally the image band 4 was classified by slicing in order to extract the coral reef areas from the map and the area and average depths of each reef were calculated using the manually digitized images. Maps were validated using field data. Pearson correlation coefficient was used to find the correlation between true field depth and the calculated depth. To determine whether there is a difference between true depth and calculated depth, pairedsample $\mathrm{T}$ test was carried out. 


\section{Results}

\section{Colour composites}

Combination of band 3, 2 and 1 respectively for red, green and blue produces true colour composite. True colour composite of study area in southern coast of Sri Lanka with the reef areas is shown in Figure 2.

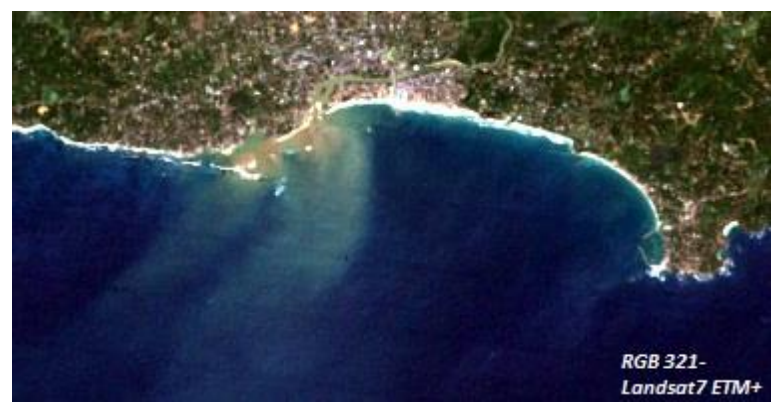

Figure 2. True colour composite of Landsat ETM+ bands in study area.

Several other colour composites were produced by different band combinations. Some of them are shown in Figure 3.
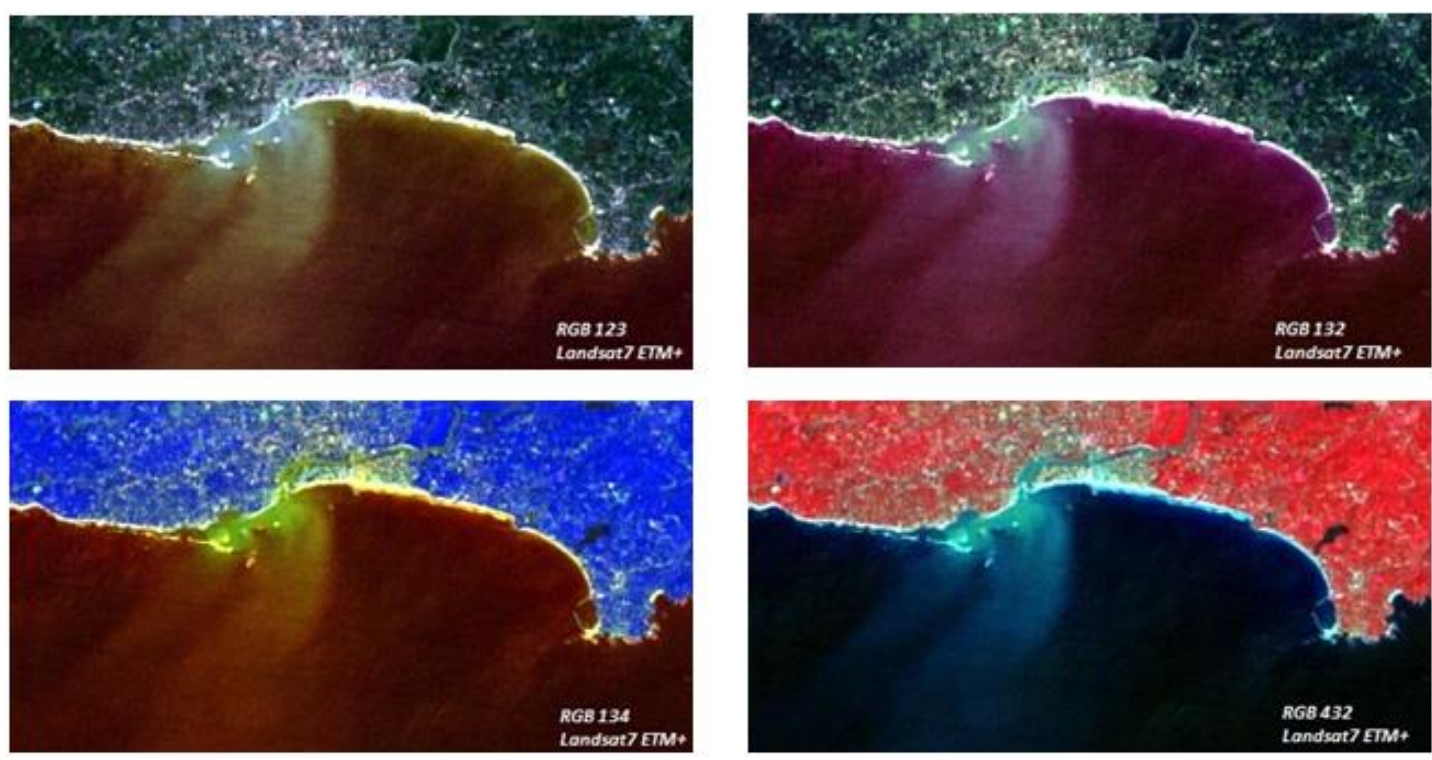

Figure 3.Some of other colour composites of Landsat ETM+ bands in the study area. 


\section{Bathymetry map of coral reefs in Dondra, Polhena and Madiha}

For the preparation of bathymetry map following data which were used for the calculations were calculated from the image bands.

\section{Digital Number (DN) values of deep sea}

DN values for deep sea ( $>50 \mathrm{~m})$ of each bands were estimated from the image bands which have been assigned the field depth and depths taken from the hydrographic chart. These are given in Table 1.

Table 1.Estimateddeep water DN values for each band.

\begin{tabular}{lcccc}
\hline & Band1 & Band2 & Band3 & Band4 \\
\hline Deep sea maximum DN value $\left(\mathrm{L}_{\mathrm{i} \infty \max }\right)$ & 75 & 49 & 36 & 13 \\
Deep sea minimum DN value $\left(\mathrm{L}_{\text {i } \infty \text { min }}\right)$ & 69 & 41 & 31 & 12 \\
Deep sea mean DN value $\left(\mathrm{L}_{\mathrm{i} \infty \mathrm{mean}}\right)$ & 72 & 45 & 33 & 12 \\
\hline
\end{tabular}

DN values of depth of penetration (DOP) zones

Maximum and Minimum DN values for different DOP zones were found for each image band and are given in Table 2 .

Table 2.Maximum and minimum DN values for each DOP zone.

\begin{tabular}{lcccc}
\hline & Band 1 & Band 2 & Band 3 & Band 4 \\
\hline Maximum DN of the DOP zone $\left(\mathrm{L}_{\text {imax }}\right)$ & 78 & 58 & 56 & 54 \\
Minimum DN of the DOP zone $\left(\mathrm{L}_{\text {imin }}\right)$ & 76 & 50 & 37 & 14 \\
\hline
\end{tabular}

Maximum depth of penetration of DOP zones

Maximum depth of penetration for each bands were found using the field depth and depths taken from the hydrographic chart (Table 3).

Table 3: Maximum depth of Penetration in each DOP zone.

\begin{tabular}{lcccc}
\hline & Band 1 & Band 2 & Band 3 & Band 4 \\
\hline $\begin{array}{l}\text { Maximum Depth of } \\
\text { Penetration }\left(\mathrm{Z}_{\mathrm{i}}\right) / \mathrm{m}\end{array}$ & 24.5 & 15 & 11.6 & 4.2 \\
\hline
\end{tabular}




\section{Parameters needed for depth calculation}

$A_{i}, k_{i}, X_{i}$ min and $X_{i \text { max }}$ which were calculated using equations $6,7,8,9$ respectively are given in Table 4.

Table 4.Calculated parameters for bathymetry map calculation for each band.

\begin{tabular}{lllll}
\hline & Band 1 & Band 2 & Band 3 & Band 4 \\
\hline $\mathrm{X}_{\mathrm{i} \max }$ & 1.7918 & 2.5649 & 3.1355 & 3.7377 \\
$\mathrm{X}_{\mathrm{i} \min }$ & 1.3863 & 1.6094 & 1.3863 & 0.6931 \\
$\mathrm{k}_{\mathrm{i}}$ & 0.0213 & 0.1405 & 0.1182 & 0.3624 \\
$\mathrm{~A}_{\mathrm{i}}$ & 2.4320 & 5.8249 & 4.1283 & 3.7377 \\
\hline
\end{tabular}

The bathymetry map, which was created by assembling of four separate calculated sub maps is given in Figure 4. Land area of the map was masked because land and reef area cannot be distinguished clearly due to some similar reflectance processes for both sea and land. Land masking gives the clear picture of bathymetry map of coral reef areas.

According to the Pearson correlation coefficient, there is a high correlation between true depth and calculated depth of coral reef bathymetry map $(r=0.921 ; p<0.05)$. Paired $t$ test also proved that there is no significant difference between true depth and calculated depth $(\mathrm{p}>0.05)$.

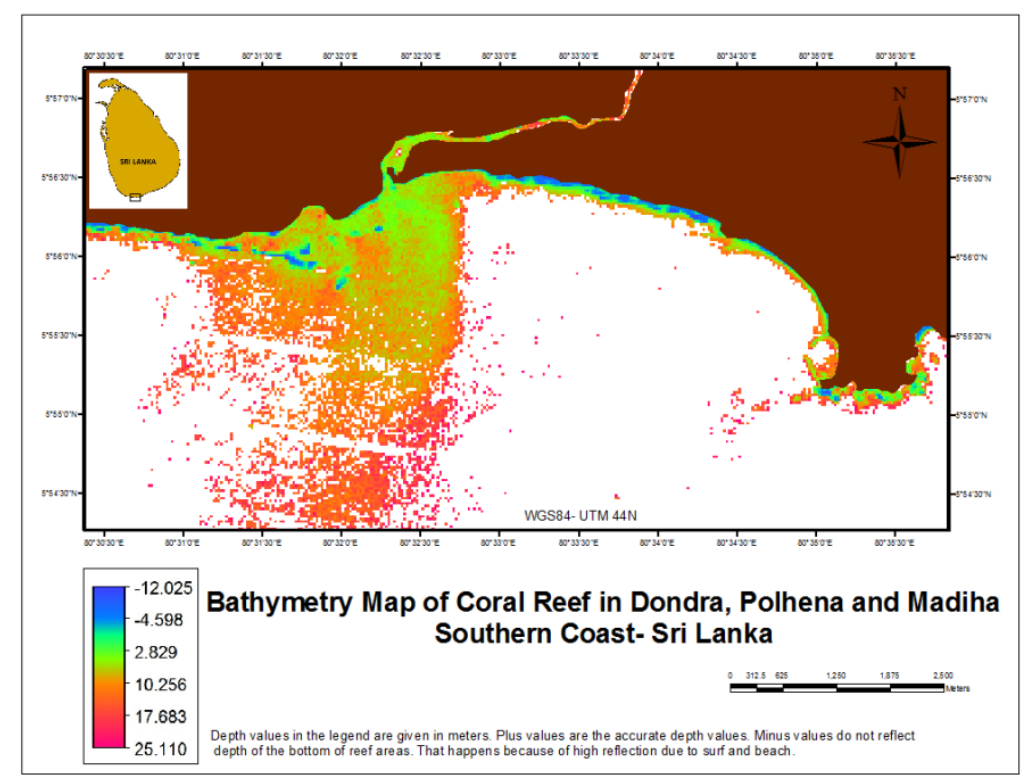

Figure 4.Bathymetry map of coral reefs in Dondra, Polhena and Madiha. 
Map lists created from different depth calculated bands

Some of the maps created from depth calculated band combinations are given in Figure 5.

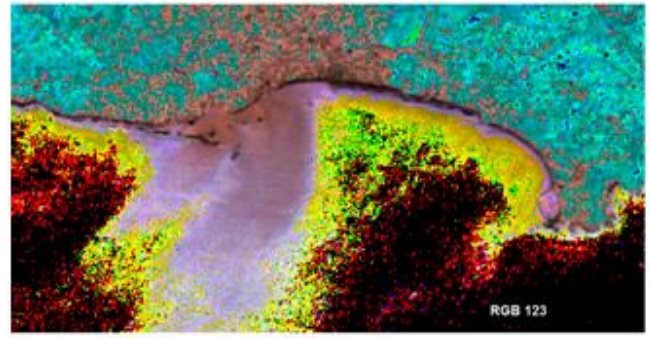

(a): (RGB123)

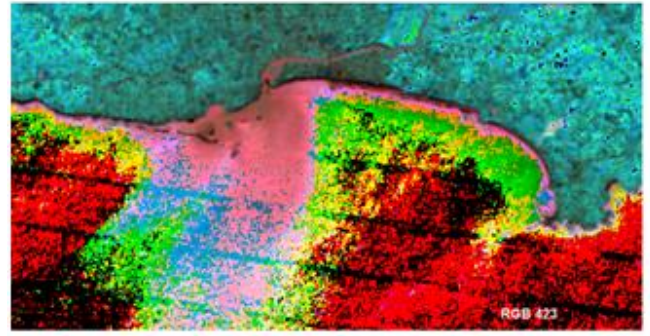

(c): (RGB423)

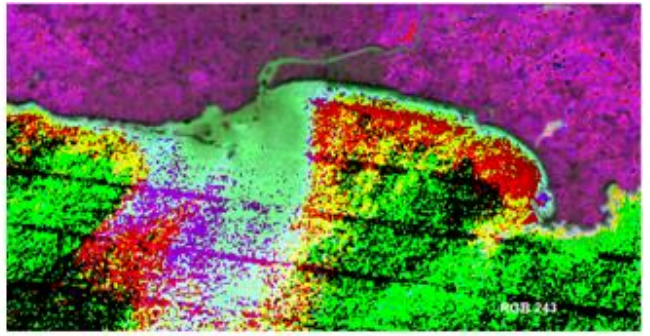

(b): (RGB243)

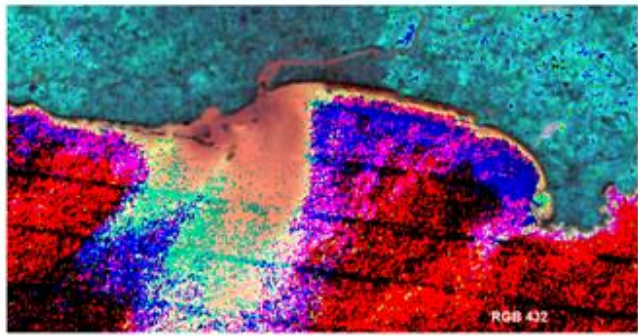

(d): (RGB432)

Figure 5. Map lists created from depth calculated bands.

The combination of depth calculated bands through depth of penetration bathymetry mapping method, gives various colouration according to the depth variation as well as bottom characteristics. Therefore, different zones canbe visualized in different colors which help to recognise the coral reef areas from other landuse paterns and the ocean surface characteristics. Figure 5 (a) shows the combination of depth calculated sub maps of band 1,2 and 3 while figure 5 (b), (c) and (d) show the combination of depth calculated maps of band 2, 3 and 4. Comparission of all these figures shows that combining of sub map of band 4 gives very clear picture of coral reef arears which reflects as dark patches close to the shoreline in the ocean region in maps of figure 5. This clear demarcation can be seen on figure 5 (b), (c) and (d) as the band 4 contribute to them. Therefore to demmarcate the shallow coral reef, the band 4 is the most suitable band. 


\section{Image classification (Slising)}

Classification was carried out to sub map 4. The classified map is shown in Figure 6.

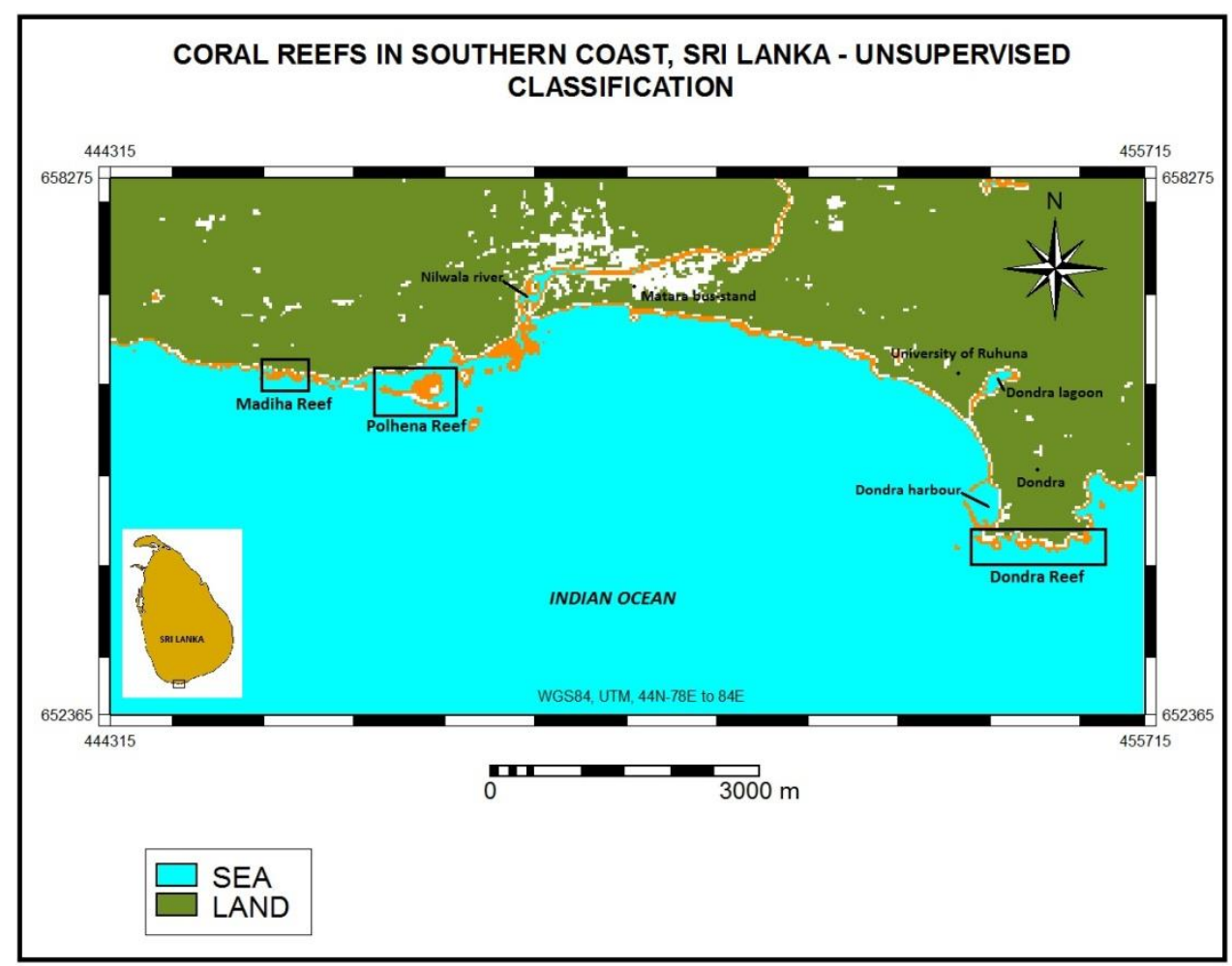

Figure 6.Classified map of coral reefs in Madiha, Polhena and Dondra.

Using histogram of band 4 (Figure 7), unsupervised classification was carried out to extract coral reef areas in the map. Band 4 was used because it is the only band which gives the clear cut of coral reef area as the band reflect the solar energy from only the shallow bottom where coral reefs are located. Hence more precise locations could be delineated using band 4 rather than other bands, i.e., band 1, 2, 3 etc. 


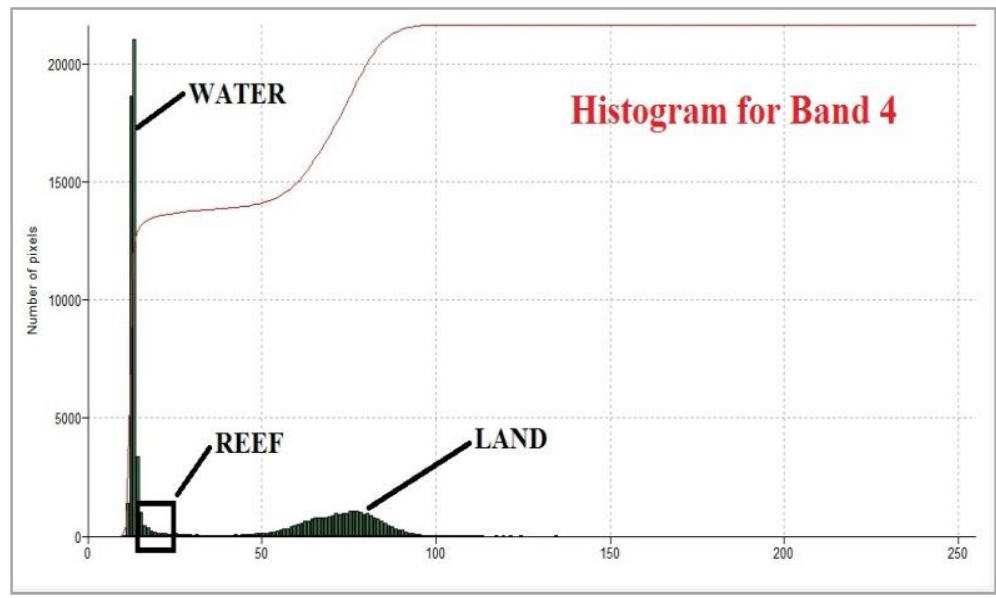

Figure 7. Histogram of band 4

\section{Area and Average Depth calculation}

Area of the three coral reefs calculated from the classified image, average depths of three coral reefs calculated from the bathymetry map and average depth calculated from the depth data obtained from the field are given in Table 5.

Table 5. Calculated areas and average depths.

\begin{tabular}{llll}
\hline Coral Reef & Area $\left(\mathrm{m}^{2}\right)$ & $\begin{array}{l}\text { Average depth from } \\
\text { bathymetry map }(\mathrm{m})\end{array}$ & $\begin{array}{l}\text { Average depth from } \\
\text { the field }(\mathrm{m})\end{array}$ \\
\hline Dondra Reef & 85500 & $1.83 \pm 0.79$ & $1.59 \pm 0.55$ \\
Polhena Reef & 240300 & $1.46 \pm 1.23$ & $1.39 \pm 0.78$ \\
Madiha Reef & 51300 & $1.81 \pm 0.99$ & $1.56 \pm 0.61$ \\
\hline
\end{tabular}

After finalizing the map, the accuracy was tested using the Pearson correlation. The correlation coefficient $(r=0.921)$ indicates that there is a significant correlation between true depth and the calculated depth from the map. For this correlation estimation, measured depths during the field survey were used with the calculated depth. Standard deviation of the calculated depth was 4.81 and the standard error was 0.85 .There is no significant difference between True depth and the calculated depth $(\mathrm{p}>0.05)$. According to One-way ANOVA, there is a significant difference in depth values between the coral reef areas $(\mathrm{p}<0.05)$. 


\section{Discussion}

Remote sensing techniques are often more cost effective in gathering information over vast and remote areas without a restriction of shallowness (Vanderstraete et al. 2003). Landsat7 ETM+ satellite images were used for mapping selected coral reefs in southern coast of Sri Lanka because it is easy to access data sources on the internet which are freely available. In addition to that there are several advantages of using Landsat images such as availability of eight bands captured for different wavelengths of electromagnetic spectrum, moderate spatial resolutions $(15 \mathrm{~m}, 30 \mathrm{~m}, 60 \mathrm{~m})$, etc. Out of those bands only first four bands were used for mapping of reef areas as they have the significant characteristics that reflect the bottom characteristics. 'The sea bed can reflect enough light to be detected by a satellite sensor up to a depth of $30 \mathrm{~m}$ (Green et al. 2000 cited in Vanderstraete et al. 2003).

"Depth of Penetration" mapping method was developed by Jupp (1988) and modified by Green et al. (2000) was used for mapping the bathymetry of coral reef habitats as it is a reliable method. According to the method several parameters had to be found from the bands. At the beginning mean DN (digital number) value of the deep water for the different four bands were found through respective bands. Here the deep water was defined as the water deeper than $50 \mathrm{~m}$, because at this depth light doesn't reach the bottom. Mean DN values for deep water were taken using the maximum and minimum DN value for the deep water. Highest mean deep water DN value belongs to band 01 (72) while lowest value belongs to band 04 (12), which means highest reflectance is given by band 01 and lowest reflectance is given by band 04. Maximum and minimum DN values for DOP (Depth of penetration) zone 01 (band 01 ) were 78 and 76 respectively while those values of zone 02 (band 02) were 54 and 14 respectively. Then maximum depth of penetration for each DOP zone was determined with the aid of depth taken from the hydrographic map given by NARA. Maximum depth of penetration of band 01 is $24.5 \mathrm{~m}$ and maximum depth of penetration of band 04 is $4.2 \mathrm{~m}$.

Assemblage of those DOP zones gives the final bathymetry map of the reef area. According to the final map depth variation in reef can be observed and calculated depth can be visualized. Results show that the Polhena reef extends to vast area compare to other two reefs; Dondra and Madiha. As Madiha reef is very much closer to and smaller than Polhena reef, it does not reflect the clear cut appearance on the bathymetry map. However, the precise location of the reef with specific reflectance characteristics could be noted. Other main difficulty in identifying the Madiha reef is its 
approximation to the land. Since Dondra reef is far away from the Polhena reef, it is possible to differentiate the Dondra reef patches from other nearby areas. However, there is also a confusion with the land characteristics which are shown in the map, because this reef is also very close to the land. The reason for this similar colouration due to similar reflectance in both the reef areas and land is some similar objective characteristics. Furthermore during low tide, the reef is exposed. Hence at that time the reflectance of the reef is similar to that of the land surface. However, in this mapping method, land reflection had to discard because the calculations used were acceptable only for reflectance occurred in sea and submerged reef areas. Nevertheless, these coral reef areas can be visualized from the final bathymetry map.

Some unacceptable depth-values were observed close to the reef areas (areas in blue colour). This is actually due to the reflectance of the breaking of surf at the edge of the reefs. At those areas, reflectance becomes very high and gives minus depth values. Therefore, this reflectance cannot be used for bathymetry mapping. However, that surf break gives the clue that there is a reef. Between Polhena and Dondra reefs there are some blue colour patches very close to the shore in bathymetry map. These are also break of the surf. Some islets also have high reflectance due to the land characteristics. The Polhena reef area is shallow not only due to the coral reef but also due to the sand accumulation by the nearest outfall of Nilwala River. Therefore, to get a proper idea about the reef area through the bathymetry map, conformation from the field observation is absolutely necessary.

One of the major problems in the type of analysis is the errors that occur in the finding of depth from the contour maps. Coordinates may slightly vary with the depth values. This slight variation can drastically affect the map calculation when these points are assigned to the map. Then this will give wrong correlation between DN value and the depth. Therefore more accurate more depth values are needed. Other main restriction is that single pixel represents $900 \mathrm{~m}^{2}$ of the reef area. Therefore variation of bottom substrate of reefs within that pixel is not reflected. As the coral reefs are heterogeneous, for more detailed description, there should be high resolution satellite images.

Accuracy can be increased by applying atmospheric and radiometric correction to the image bands. Several assumptions are considered in this mapping method such as the homogeneity of the substrate in different DOP zones. Since substrates are not actually homogenous, some errors can occur in the map processing. Changes in the water conditions and water quality also affect the reflectance. Another problem encountered during map processing was the distortion of some areas on bands due to the sensor damage. However, there was not a severe problem as the damage was outside the study area. 
Areas of coral reefs were estimated from the map. For this purpose, digitizing of reefs was carried out with the maximum possible accuracy. According to the histogram and digitized map the highest reef area was represented by the Polhena reef ( 24.03 ha) while lowest area was represent by the Madiha reef (5.13 ha). Area of the Dondra reef is $8.55 \mathrm{ha}$.

According to the bathymetry map maximum depth of $1.83 \mathrm{~m}$ was recorded in Dondra reef while the lowest depth was recorded in Polhena reef $(1.46 \mathrm{~m})$. Some parts of the Polhena reef expose during the low tide. The mean depth of Madiha reef is $1.81 \mathrm{~m}$, which is very close to the depth of Dondra reef. Madiha reef also get exposed at low tide. Normally the corals in Madiha are aggregated around the fringing area and they extend to deep water too. Therefore, average depth can be higher than the expected value. Other reasons for having some unexpected depth values may be digitizing errors that are encountered during the map calculations. However, the depth values can be considered as reasonable.

\section{Conclusions}

Mapping of coral reefs using remote sensing can be applied for shallow coral reefs. Landsat 7 ETM+ images can be used to identify the reef areas alone with the reflectance characteristics of different bands. Shallow reef areas give high DN values in the ocean due to the bottom reflection. As reef areas are shallow, using these reflectance values coral reef areas can be identified. These identified reefs can be validated by field surveys. Due to the limited resolution of the Landsat images, very small $(<30 \mathrm{~m}$ diameter) reef patches cannot be identified clearly. Therefore, Landsat images should be used for large reefs which are more than $30 \mathrm{~m}$ in length. Bathymetry mapping of reef areas gives the more descriptive details on bottom nature of the reefs. Band 4 of the Landsat ETM+ images is the most suitable band for image classification for identification and distribution of coral reefs. Using those maps the reef extent, reef margins and distributions of the reef can be identified. These maps can be used for development projects in the reef areas in the coastal and marine regions.

\section{Acknowledgements}

Facilities for this research were produced the Department of Oceanography and Marine Geology of Faculty of Fisheries and Marine Sciences \& Technology, University of Ruhuna, Sri Lanka. Special thanks are due to National Hydrographic office of National Aquatic Resources Research and Development Agency (NARA) for providing me the Hydrographic chart for the research. 


\section{References}

Hoover J.P. 1998.

Hawaii's Sea Creatures: A Guide to Hawaii's Marine Invertebrates. $1^{\text {st }}$ edition. Mutual Publishing, New Jersey.

Joseph L. 2005.

National Report of Sri Lanka on the Formulation of a Transboundary Diagnostic Analysis and Strategic Action Plan for the Bay of Bengal Large Marine Ecosystem Programme. http://www.boblme.org/ document Repository/Nat_Sri_Lanka.pdf [Accessed 01 May 2012].

Jupp D. 1988.

Background and extensions to Depth of penetration (DOP) mapping in shallow coastal waters, proceedings of the symposium on Remote Sensing of the Coastal Zone, Brisbane, Department of Geographic Information pp. IV. .1-IV.2.19.

Mumby P.J., E.P. Green, A.J. Edwards. \& C.D. Clark 1997.

Coral reef habitat mapping: How much detail can remote sensing provide? Marine Biology 130:193-202.

Nadaoka K., E.C. Paringit \& H. Yamano 2004.

Remote sensing of coral reefs in Japan, Coral Reefs of Japan (Ministry of the Environment and Japanese Coral Reef Society, editors).Ministry of the Environment, Tokyo pp. 89-102.

Pradeep Kumara P.B.T., O. Linden, D.W. Souter \& P.R.T. Cumaranatunga 2005.

Coral transplantation: an additional tourist attraction in Polhena reef of Southern Sri Lanka. Proceedings of 10th International coral reef symposium 2005, Okinawa, Japan pp. 452

Vanderstraete T., R. Goossens \& T.K. Ghabour2003.

Remote sensing as a tool for bathymetric mapping of coral reefs in the Red Sea (Hurghada-Egypt). Belgium: Research Assistant of the Fund for Scientific Research. www.vliz.be/imisdocs/publications/118860.pdf [Accessed 02 May 2012]. 